\title{
Predictors for Early Identification of Hepatitis C Virus Infection
}

\author{
Mei-Hua Tsai, ${ }^{1,2}$ Kuei-Hsiang Lin, ${ }^{3}$ Kuan-Tsou Lin, ${ }^{1}$ \\ Chi-Ming Hung, ${ }^{1}$ Hung-Shiang Cheng, ${ }^{4}$ Yu-Chang Tyan, ,6,7 \\ Hui-Wen Huang, ${ }^{8,9}$ Bintou Sanno-Duanda, ${ }^{2,10}$ Ming-Hui Yang, ${ }^{6,11}$ \\ Shyng-Shiou Yuan, ${ }^{6,11,12,13}$ and Pei-Yu Chu ${ }^{2,14}$ \\ ${ }^{1}$ Kaohsiung Blood Center, Taiwan Blood Services Foundation, Kaohsiung 811, Taiwan \\ ${ }^{2}$ Department of Medical Laboratory Science and Biotechnology, College of Health Sciences, Kaohsiung Medical University, \\ Kaohsiung 807, Taiwan \\ ${ }^{3}$ Department of Clinical Laboratory, School of Medicine, College of Medicine, Kaohsiung Medical University, \\ Kaohsiung 807, Taiwan \\ ${ }^{4}$ Cishan Hospital, Ministry of Health and Welfare, Kaohsiung 842, Taiwan \\ ${ }^{5}$ Department of Medical Imaging and Radiological Sciences, College of Health Sciences, Kaohsiung Medical University, \\ Kaohsiung 807, Taiwan \\ ${ }^{6}$ Translational Research Center, Kaohsiung Medical University Hospital, Kaohsiung 807, Taiwan \\ ${ }^{7}$ Institute of Medical Science and Technology, National Sun Yat-Sen University, Kaohsiung 804, Taiwan \\ ${ }^{8}$ Department of Anesthesiology, Chang Gung Memorial Hospital-Kaohsiung Medical Center, \\ Chang Gung University College of Medicine, Kaohsiung 833, Taiwan \\ ${ }^{9}$ Department of Biological Sciences, National Sun Yat-Sen University, Kaohsiung 804, Taiwan \\ ${ }^{10}$ Edward Francis Small Teaching Hospital, Banjul 1515, Gambia \\ ${ }^{11}$ Department of Medical Research, Kaohsiung Medical University Hospital, Kaohsiung 807, Taiwan \\ ${ }^{12}$ Department of Obstetrics and Gynecology, Kaohsiung Medical University Hospital, Kaohsiung 807, Taiwan \\ ${ }^{13}$ School of Medicine, College of Medicine, Kaohsiung Medical University, Kaohsiung 807, Taiwan \\ ${ }^{14}$ Department of Laboratory Medicine, Kaohsiung Medical University Hospital, Kaohsiung 807, Taiwan
}

Correspondence should be addressed to Pei-Yu Chu; peiyuchu@kmu.edu.tw

Received 8 September 2014; Accepted 28 November 2014

Academic Editor: Mohammad Ahmad Al-Shatouri

Copyright (c) 2015 Mei-Hua Tsai et al. This is an open access article distributed under the Creative Commons Attribution License, which permits unrestricted use, distribution, and reproduction in any medium, provided the original work is properly cited.

Hepatitis $\mathrm{C}$ virus (HCV) infection can cause permanent liver damage and hepatocellular carcinoma, and deaths related to HCV deaths have recently increased. Chronic HCV infection is often undiagnosed such that the virus remains infective and transmissible. Identifying HCV infection early is essential for limiting its spread, but distinguishing individuals who require further HCV tests is very challenging. Besides identifying high-risk populations, an optimal subset of indices for routine examination is needed to identify HCV screening candidates. Therefore, this study analyzed data from 312 randomly chosen blood donors, including 144 anti-HCV-positive donors and 168 anti-HCV-negative donors. The HCV viral load in each sample was measured by real-time polymerase chain reaction method. Receiver operating characteristic curves were used to find the optimal cell blood counts and thrombopoietin measurements for screening purposes. Correlations with values for key indices and viral load were also determined. Strong predictors of HCV infection were found by using receiver operating characteristics curves to analyze the optimal subsets among red blood cells, monocytes, platelet counts, platelet large cell ratios, and mean corpuscular hemoglobin concentrations. Sensitivity, specificity, and area under the receiver operator characteristic curve $(P<0.0001)$ were $75.6 \%$, 78.5\%, and 0.859 , respectively. 


\section{Introduction}

According to the World Health Organization, deaths from primary hepatocellular carcinoma (HCC) exceeded 1 million in 2010. The leading risk factors for $\mathrm{HCC}$ are hepatitis $\mathrm{B}$ virus (HBV) and hepatitis $\mathrm{C}$ virus (HCV) infections [1]. HCC is known to be the most common form of liver cancer and the third leading cause of cancer-related deaths worldwide [2]. Unlike HBV infection, at present, there is no vaccine to prevent HCV infection approved by the Food and Drug Administration (FDA) $[3,4]$. The global prevalence of HCV antibodies is $0.5 \%-2 \%$ and, in Taiwan, the average seropositive rate is $4.4 \%$, but may exceed $30 \%$ in mountainous or coastal regions [5-7]. Further, genotype $1 \mathrm{~b}$ is reportedly a major risk factor for HCC [8]. In southern Taiwan, the reported prevalence of HCV genotype $1 \mathrm{~b}$ is $50-60 \%$ and that of $2 \mathrm{a}$ is $30-40 \%$ [8]. These figures are consistent with an earlier international survey of $\mathrm{HCV}$ in blood donors, which revealed that $57 \%$ were infected with HCV type 1 and $43 \%$ were infected with HCV type $b$ [9]. The increased morbidity and mortality rate prevailing in $\mathrm{HCV}$ infection and the increased burden of HCV-related infections have attracted widespread attention, with potential slow evolving characteristics at rapidly progressive signatures causing greater impact on public health [10-13]. Risk factors include frequent exposure to blood or contaminated needles. In the USA, birth during the baby boom era (1945-1965) was also recommended for inclusion as an HCC risk factor [14]. One reason why HCV remains a major public health threat is the difficulty of developing an effective treatment strategy because $\mathrm{HCV}$ is characterized by long episodes during which the patient is asymptomatic, even after liver damage has occurred.

In a high percentage (54\%-86\%) of cases, HCV infection persists for many decades and ultimately causes liver cirrhosis or HCC [15]. Therefore, early detection of HCV infection is essential not only to enable initiation of HCV therapy sufficiently early to prevent disease progression but also to prevent further transmission. Recombinant immunoblot assay (RIBA) and nucleic acid test (NAT) methods have relatively high specificity for detecting HCV but are not cost effective $[12,14,16]$. Although developing a test for identifying HCV at an early stage is challenging, such a test is urgently needed for initially identifying HCV in endemic geographic locations where the risk is high. In haematopoietic cells, HCV interferes with peripheral blood maturation and causes thrombocytopenia [17]. Thrombocytopenia also occurs in HCV infection and in liver cirrhosis [18-21]. Notably, patients with liver fibrosis or cirrhosis have abnormally low serum thrombopoietin (TPO) levels [22] since TPO is mostly produced by the liver before its release into the bloodstream [23]. Thrombopoietin is the main regulator of platelet production, and a feedback loop between circulating TPO and platelet mass has been reported [24]. However, little is known regarding platelet count (PLT) and TPO levels in apparently healthy people.

A complete blood count (CBC) is one of the most commonly performed blood tests. Since it reveals peripheral blood changes, the CBC is routinely performed in health examinations, even in asymptomatic patients. However, there is no evaluation showing the screen for $\mathrm{HCV}$ potential infection by $\mathrm{CBC}$ data. The objective of this study was to identify an optimal subset of routinely obtained haematological indices that can be used to discriminate potential HCV infection cases from the general population. Further, the change of TPO levels in apparently healthy people was also examined.

\section{Materials and Methods}

2.1. Subjects. Blood samples were obtained from the Kaohsiung Blood Center between January 2008 and December 2009. Before transfusion, all blood donors were required to complete a "Blood Donor Registration Form" http://intra .blood.org.tw/upload/b1f25843-f5f6-4c91-b483-6b81d417a133 .pdf and to undergo an interview regarding health condition and lifestyle in order to estimate blood quality. The blood samples were subjected to tests for transfusion-transmissible infections, including the RPR and TPPA tests for syphilis and tests for HBsAg, anti-HCV, and anti-HTLV I/II. In each of the 144 randomly selected subjects in the experimental group in this study, HBsAg (-), anti-HIV (-), anti-HTLV I/II (-), anti-HCV (+), or HCV which was confirmed by sera positive for anti-HCV and positive for either HCV RNA or RIBA. The other 168 randomly selected subjects with HBsAg (-), anti-HIV (-), anti-HCV (-), or anti-HTLV I/II $(-)$ infection were enrolled in the negative control group. No data were collected until signed consent forms were received from each participant. This study was approved by the Ethics Committee of the Taiwan Blood Services Foundation.

2.2. Laboratory Tests. Anti-HCV-positive cases were identified by a Murex anti-HCV (Version 4.0) enzyme immunoassay (Abbott, South Africa) in enzyme-linked immunosorbent assay (ELISA). The following measurements were performed according to the manufacturer instructions: CBC counts were measured with a Sysmex XT-1800i autoanalyser (Sysmex, Japan), alanine aminotransferase (ALT) levels were measured with an AU7200 autoanalyser (Beckman Coulter, USA), and serum TPO levels were measured by ELISA (Quantikine; R\&D Systems Europe, Oxfordshire, UK). The HCV RNA viral loads were measured by real-time PCR using the COBAS AmpliPrep/COBAS TaqMan HCV Test (Roche Molecular Systems, USA). A RIBA (Chiron RIBA HCV 3.0 Strip Immunoblot Assay, Novartis Vaccines and Diagnostics, USA) was performed to verify positive responses to anti-HCV.

2.3. Statistical Analysis. Statistical analyses were performed using JMP software (Version 9.0, SAS Institute Inc., Cary, NC, USA). Chi-square test and Student's $t$-test were used to compare demographic characteristics and clinical measurements between the HCV-positive experimental group and the HCV-negative control group. The analysis of covariance (ANCOVA) was used to compare haematological indices, including alanine transaminase (ALT) and TPO levels, between the 2 groups, with adjustment for gender and age. Stepwise multiple logistic regression analysis was used to evaluate variables for associations with $\mathrm{HCV}$ infection. 
Receiver operating characteristic (ROC) analysis was performed to calculate the sensitivity and specificity, area under the ROC curve (AUROC), and the optimal cut-off value. Correlations between key parameters and $\mathrm{HCV}$ viral loads were calculated using Spearman correlation. A $P$ value less than 0.05 was considered statically significant.

\section{Results}

3.1. Study Population. Table 1 shows the basic demographic characteristics of participants in the HCV-infected group (83 men and 61 women; mean age $=39.3 \pm 10.8 \mathrm{y})$ and in the negative control group ( 38 men and 130 women; mean age $=$ $37.4 \pm 7.3 \mathrm{y})$. Out of $144 \mathrm{HCV}$-positive cases, $24(16.7 \%)$ showed serum HCV RNA negativity. The median (interquartile range, IQR) HCV viral load was 517556.0 (10119.53418142.0) IU/mL.

3.2. Effects of HCV Infection on Haematological Indices. Table 1 also shows that platelet-related indices significantly differed between the $\mathrm{HCV}$-infected group and the negative control group. Compared with the control group, the HCVinfected group had significantly lower platelet counts (PLT) and plateletcrit counts (PCT) but significantly higher platelet distribution widths (PDW), mean platelet volumes (MPV), and platelet-large cell ratios (P-LCR). Restated, the HCVinfected group had lower PLT and PCT but higher MPV, PDW, and P-LCR. This implied that the HCV-infected group had larger, more irregular, and more numerous platelets compared to the controls.

Compared with the negative control group, the HCVinfected group showed significantly higher red blood cell counts (RBC), haemoglobin (Hb) levels, and haematocrit (HCT) levels (Table 1). Compared with the control group, the $\mathrm{HCV}$-infected group also showed significantly higher white blood cell counts (WBC), lymphocyte counts, and monocyte counts (MONO). Notably, Hb, HCT, and all four cell counts (RBC, WBC, lymphocytes, and MONO) were higher in the $\mathrm{HCV}$-infected group than in the control group.

3.3. Effects of HCV Infection on TPO and ALT Levels. Mean TPO levels were significantly higher in the HCV-infected group than in the negative control group $(74.0 \pm 66.55 \mathrm{pg} /$ $\mathrm{mL}$ versus $42.04 \pm 37.89 \mathrm{pg} / \mathrm{mL}$, resp.; $t$-test, $P<0.001$; ANCOVA, $P<0.001$; Mann-Whitney, $P<0.0001)$. However, mean ALT levels did not significantly differ between the $\mathrm{HCV}$-infected group and the negative control group (35.5 \pm $45.0 \mathrm{IU} / \mathrm{L}$ versus $23.3 \pm 29.5 \mathrm{IU} / \mathrm{L}$, resp.; $t$-test, $P=0.006$; ANCOVA, $P=0.339$; Mann-Whitney, $P<0.0001$ ).

3.4. Comparative Prediction Performance of Haematological Indices. Stepwise multiple logistic regression analysis was performed to identify haematological indices, ALT factors, and TPO factors that predict $\mathrm{HCV}$ infection. The $\mathrm{HCV}$ infection status was used as the dependent variable; haematological indices, ALT, and TPO were used as independent variables. The model revealed seven significant predictors: mean corpuscular haemoglobin concentration (MCHC), RBC, PLT, MPV, P-LCR, MONO, and TPO (Table 2). Analysis of
TABLE 1: Comparison of demographic characteristics and clinical measurements in the HCV-infected group and in the negative control group.

\begin{tabular}{|c|c|c|c|c|}
\hline Variable & $\begin{array}{c}\mathrm{HCV} \text {-infected } \\
\text { group } \\
(n=144)\end{array}$ & $\begin{array}{c}\text { Negative } \\
\text { control group } \\
(n=168)\end{array}$ & $\begin{array}{c}t \text {-test } \\
P\end{array}$ & $\begin{array}{c}\text { ANCOVA } \\
P^{\#}\end{array}$ \\
\hline \multicolumn{5}{|l|}{ Gender $n(\%)$} \\
\hline Male & $83(57.6)$ & $38(22.6)$ & & \\
\hline Female & $61(42.4)$ & $130(77.4)$ & $<0.001$ & \\
\hline Age mean (sd) & $39.3 \pm 10.8$ & $37.4 \pm 7.3$ & 0.071 & \\
\hline $\mathrm{WBC}\left(\times 10^{3} \mu \mathrm{l}\right)$ & $6.8 \pm 1.9$ & $6.0 \pm 1.7$ & $<0.001$ & 0.006 \\
\hline $\mathrm{RBC}\left(\times 10^{6} \mu \mathrm{l}\right)$ & $4.9 \pm 0.7$ & $4.5 \pm 0.5$ & $<0.001$ & 0.024 \\
\hline $\mathrm{HB}(\mathrm{g} / \mathrm{dl})$ & $14.7 \pm 1.5$ & $13.4 \pm 1.8$ & $<0.001$ & $<0.001$ \\
\hline HCT (\%) & $43.0 \pm 3.9$ & $39.8 \pm 4.4$ & $<0.001$ & 0.001 \\
\hline MCV (fl) & $89.1 \pm 8.0$ & $88.1 \pm 6.3$ & 0.243 & 0.122 \\
\hline $\mathrm{MCH}(\mathrm{pg})$ & $30.5 \pm 3.1$ & $29.6 \pm 2.8$ & 0.008 & 0.030 \\
\hline $\mathrm{MCHC}(\mathrm{g} / \mathrm{dl})$ & $34.2 \pm 1.0$ & $33.5 \pm 1.3$ & $<0.001$ & 0.005 \\
\hline $\operatorname{PLT}\left(\times 10^{3} \mu l\right)$ & $222.3 \pm 58.8$ & $270.5 \pm 61.8$ & $<0.001$ & $<0.001$ \\
\hline $\mathrm{NEU}(\%)$ & $56.4 \pm 9.0$ & $58.3 \pm 8.2$ & 0.052 & $<0.001$ \\
\hline LYM (\%) & $34.0 \pm 8.2$ & $33.1 \pm 7.7$ & 0.270 & 0.648 \\
\hline MONO (\%) & $6.6 \pm 1.8$ & $5.7 \pm 1.4$ & $<0.001$ & $<0.001$ \\
\hline EOS (\%) & $2.5 \pm 1.6$ & $2.4 \pm 1.7$ & 0.630 & 0.174 \\
\hline BAS (\%) & $0.5 \pm 0.3$ & $0.5 \pm 0.3$ & 0.140 & 0.230 \\
\hline RDW-SD (fl) & $41.8 \pm 2.9$ & $42.6 \pm 2.9$ & 0.013 & 0.055 \\
\hline RDW-CV (\%) & $13.3 \pm 1.5$ & $13.6 \pm 1.5$ & 0.040 & 0.034 \\
\hline PDW (fl) & $13.2 \pm 2.0$ & $12.1 \pm 1.9$ & $<0.001$ & $<0.001$ \\
\hline MPV (fl) & $10.8 \pm 0.8$ & $10.5 \pm 0.9$ & $<0.001$ & 0.001 \\
\hline P-LCR (\%) & $31.7 \pm 6.2$ & $28.5 \pm 6.4$ & $<0.001$ & $<0.001$ \\
\hline PCT (\%) & $0.2 \pm 0.1$ & $0.3 \pm 0.1$ & $<0.001$ & $<0.001$ \\
\hline $\operatorname{NEUT}\left(\times 10^{3} \mu \mathrm{l}\right)$ & $3.9 \pm 1.4$ & $3.6 \pm 1.3$ & 0.034 & 0.090 \\
\hline LYMPH $\left(\times 10^{3} \mu \mathrm{l}\right)$ & $2.3 \pm 0.7$ & $1.9 \pm 0.6$ & $<0.001$ & 0.004 \\
\hline $\operatorname{MONO}\left(\times 10^{3} \mu \mathrm{l}\right)$ & $0.4 \pm 0.1$ & $0.3 \pm 0.1$ & $<0.001$ & $<0.001$ \\
\hline $\operatorname{EOS}\left(\times 10^{3} \mu \mathrm{l}\right)$ & $0.2 \pm 0.1$ & $0.1 \pm 0.1$ & 0.083 & 0.561 \\
\hline $\operatorname{BAS}\left(\times 10^{3} \mu \mathrm{l}\right)$ & $0.03 \pm 0.02$ & $0.03 \pm 0.02$ & 0.463 & 0.789 \\
\hline TPO (pg/ml) & $74.4 \pm 66.3$ & $42.0 \pm 37.9$ & $<0.001$ & $<0.001$ \\
\hline ALT (IU/L) & $35.5 \pm 45.0$ & $23.3 \pm 29.5$ & 0.006 & 0.339 \\
\hline
\end{tabular}

HCV: hepatitis C virus; ANCOVA: analysis of covariance; WBC: white blood cell count; RBC: red blood cell count; Hb: haemoglobin; HCT: haematocrit; $\mathrm{MCV}$ : mean corpuscular volume; $\mathrm{MCH}$ : mean corpuscular haemoglobin; MCHC: mean corpuscular haemoglobin concentration; RDW: RBC distribution width; PLT: platelet count; PCT: plateletcrit; PDW: platelet distribution width; MPV: mean platelet volume; P-LCR: platelet-large cell ratio; NEU: neutrophil; LYM: lymphocyte; MON: monocyte; EOS: eosinophil; BAS: basophil; TPO: thrombopoietin; ALT: alanine aminotransferase.

Significance level: $P<0.05$.

${ }^{\#}$ Age- and gender-adjusted $P$ value.

the comparative effects of values for these key factors and HCV viral load showed that PLT had a significant negative correlation with viral load $(r=-0.333, P<0.001)$ (Table 3$)$. The HCV viral load had significant positive correlations with TPO and MONO $(r=0.351, P<0.001$ and $r=0.370, P<$ 0.001 , resp.). That is, patients with elevated HCV viral loads 
TABLE 2: Results of multivariate stepwise regression analysis.

\begin{tabular}{lccc}
\hline Variables & Odds Ratio & $95 \%$ CI & $P$ \\
\hline RBC $\geq 4.76\left(\times 10^{6} \mu \mathrm{l}\right)$ & 2.043 & $1.104-3.810$ & 0.023 \\
$\mathrm{MCHC} \geq 33.9(\mathrm{~g} / \mathrm{dl})$ & 2.792 & $1.532-5.189$ & 0.001 \\
$\mathrm{PLT} \leq 258\left(\times 10^{3} \mu \mathrm{l}\right)$ & 3.124 & $1.708-5.809$ & $<0.001$ \\
$\mathrm{MPV} \geq 10.6(\mathrm{fl})$ & 0.532 & $0.091-2.331$ & 0.437 \\
$\mathrm{P}-\mathrm{LCR} \geq 28.9(\%)$ & 5.458 & $1.238-31.722$ & 0.037 \\
$\mathrm{MONO} \geq 0.38\left(\times 10^{3} \mu \mathrm{l}\right)$ & 3.504 & $1.926-6.478$ & $<0.001$ \\
$\mathrm{TPO} \geq 42.071(\mathrm{pg} / \mathrm{ml})$ & 4.673 & $2.620-8.525$ & $<0.001$ \\
\hline
\end{tabular}

Significance level: $P<0.05$; CI: confidence interval; for other abbreviations, see Table 1.

TABLE 3: Correlations between HCV viral load and values for RBC, MCHC, PLT, MPV, P-LCR, MONO, and TPO.

\begin{tabular}{lcc}
\hline Variables & $r$ & $P$ \\
\hline RBC $\left(\times 10^{6} \mu \mathrm{l}\right)$ & 0.279 & $<0.001$ \\
$\operatorname{MCHC}(\mathrm{g} / \mathrm{dl})$ & 0.217 & $<0.001$ \\
$\operatorname{PLT}\left(\times 10^{3} \mu \mathrm{l}\right)$ & -0.333 & $<0.001$ \\
P-LCR $(\%)$ & 0.194 & 0.001 \\
$\operatorname{MONO}\left(\times 10^{3} \mu \mathrm{l}\right)$ & 0.370 & $<0.001$ \\
TPO $(\mathrm{pg} / \mathrm{ml})$ & 0.351 & $<0.001$ \\
\hline
\end{tabular}

Significance level: $P<0.05$; for abbreviations, see Table 1 .

had decreased PLT whereas those with decreased PLT had elevated TPO.

An ROC analysis was then performed to determine the optimal cut-offs for the factors in a dummy-variable logistic regression model. Binary variables were coded as 1 or 0 . A stepwise procedure was used to select an optimal subset of dummy regressors and point scores. Finally, six dummy variables that showed significant differences (RBC, MCHC, PLT, P-LCR, MONO, and TPO) were identified as predictors of HCV infection and were used to construct the AUROC (range $=0.651-0.741)$ (Table 4$)$.

This method accounted for the point score whereas the final score (range $=1-7$ ) was the sum of the parameters. A score of 4 , which was considered optimal, yielded a sensitivity of $75.6 \%$ and a specificity of $78.5 \%$. The AUROC for HCV infection was $0.859(P<0.0001)$ (Figure 1). Excluding TPO, since this indicator is not performed in routine, the haematological indices routinely used to predict $\mathrm{HCV}$ infection (RBC, $\mathrm{MCHC}, \mathrm{PLT}, \mathrm{P}-\mathrm{LCR}$, and MONO) had values ranging from 1 to 5 ; a score of 3 , which was considered optimal, yielded a sensitivity of $76.8 \%$ and a specificity of $75.7 \%$. The AUROC for $\mathrm{HCV}$ infection was $0.822(P<0.0001)$ (Figure 1$)$.

\section{Discussion}

Since previous studies indicate that thrombocytopenia results from chronic liver disease, we speculated that a haematological comparison between a healthy blood donor and a donor with HCV might reveal the impact of HCV on PLT and TPO; an improved understanding of this impact could help determine whether a donor has HCV. This hypothesis

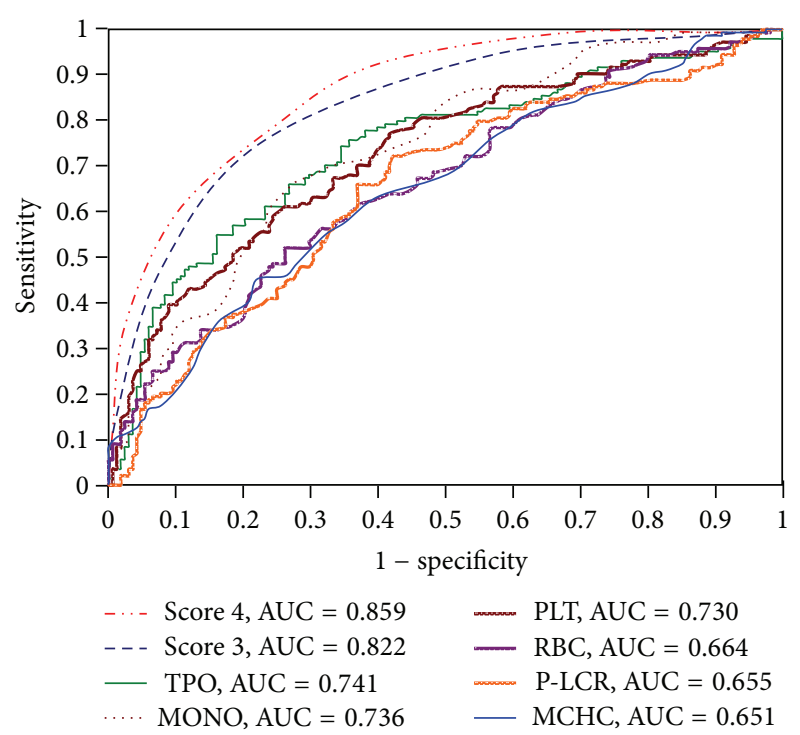

FIGURE 1: The ROC curve analysis of scores with best prognostic power for predicting HCV infection.

was tested by investigating the relationships among haematological indices and TPO and HCV viral loads. The haematological indices and TPO were also evaluated in terms of predictive performance. Because of the varying consent given by the participants, the negative control group and HCVinfected group were not matched by age or gender. Therefore, ANCOVA was used to adjust the statistical analysis for age and gender.

The data analysis indicated that ALT levels were not significantly associated with HCV infection. The ALT levels were abnormal in most hepatitis patients [25] and in most (70\%$80 \%) \mathrm{HCV}$ carriers [26]. Identifying HCV is often difficult because HCV carriers with persistently normal ALT levels are usually asymptomatic or have nonspecific symptoms. Meanwhile, MPV is not a reliable indicator as its value is known to change over time in the presence of ethylenediaminetetraacetic acid (EDTA) anticoagulant. Studies indicate that $15 \%$ to $25 \%$ of the people who recover from an initial HCV infection have persistent antibodies in the absence of the virus [27]. Thus, the $16.7 \%$ of cases who revealed positive RIBA and negative RNA in the serum HCV test in this study were most likely cases that had recovered. Further, since the window between HCV infection and detectability can exceed 70 days [28], some participants classified as anti-HCV-negative in this study may have actually been infected with HCV. Therefore, improved tools for monitoring $\mathrm{HCV}$ are urgently needed to minimize bias.

In a previous study, an HCV-infected group, which also had chronic hepatitis and cirrhosis, had a mean PLT greater than $150 \times 10^{3} \mu \mathrm{L}[20,29]$. In contrast, the mean PLT in the $\mathrm{HCV}$-infected group in this study was significantly lower than that in the control group. This difference likely resulted from the relatively lower severity of infection in the HCV-infected group in the present study, since the average seropositive rate in blood donors is much lower than that in the general 
TABLE 4: Prediction performance of haematological indices and TPO.

\begin{tabular}{lccccc}
\hline Variables & Cut-off point & AUC & Specificity & Sensitivity & $P$ \\
\hline RBC $\left(\times 10^{6} \mu \mathrm{l}\right)$ & 4.76 & 0.664 & 0.738 & 0.521 & $<0.001$ \\
MCHC $(\mathrm{g} / \mathrm{dl})$ & 33.9 & 0.651 & 0.601 & 0.632 & $<0.001$ \\
PLT $\left(\times 10^{3} \mu \mathrm{l}\right)$ & 258 & 0.730 & 0.583 & 0.771 & $<0.001$ \\
P-LCR $(\%)$ & 28.9 & 0.655 & 0.577 & 0.722 & $<0.001$ \\
MONO $\left(\times 10^{3} \mu \mathrm{l}\right)$ & 0.38 & 0.736 & 0.720 & 0.667 & 1 \\
TPO $(\mathrm{pg} / \mathrm{ml})$ & 42.07 & 0.741 & 0.643 & 0.757 & $<0.001$ \\
\hline
\end{tabular}

AUC: area under the curve value; for other abbreviations, see Table 1.

population in Taiwan $(0.07 \%$ versus $4.4 \%$, resp.) [30, 31]. Thrombocytopenia is commonly defined as a PLT below 50,000 per microlitre, which is a level commonly observed in cases of viral infection. Hypothesized mechanisms of thrombocytopenia include (1) dissemination by intravascular coagulopathies [32], (2) impairment of thrombocytopoiesis by a megakaryocyte mutation caused by the virus $[21,33,34]$, (3) direct interaction between the virus and platelets in blood circulation (e.g., phagocytosis or the aggregation, release, and thrombocytosis of platelets) [35, 36], (4) an antigen-antibody complex that impairs platelet or antiplatelet antibodies that directly antagonise platelet-specific antibodies (e.g., anti-i) [37-39], and (5) a virally caused depletion of sialic acid (containing neuraminic acids) on platelet surfaces [40]. Thrombocytopenia has also been reported in viral infections such as herpes simplex virus, vaccinia virus, human immunodeficiency virus, hantavirus, dengue II virus, and influenza virus $[35,37,41-44]$. In the current study, MPV, PDW, and P-LCR were higher in the HCV-infected group than in the control group, which indicates that large platelet formation is an inappropriate bone marrow response to thrombocytopenia.

Unlike liver cirrhosis, the mechanism of decreased PLT in HCV is decreased TPO secretion [22, 23]. In this study, platelet counts were negatively correlated with TPO levels in the HCV-infected group. Since TPO regulates the maturation of megakaryocytes and thrombocytopoiesis, increased TPO secretion which is a normal physiological response to reduced PLT might elevate PLT in blood circulation. Therefore, the reduced PLT observed in the blood circulation of the HCV infected group in this study might have resulted from increased TPO levels. In cases with both positive HCV antibodies and low PLT, HCV viremia can reportedly be predicted with $88.8 \%$ accuracy [45]. The HCV RNA viral load is a useful indicator for monitoring the course of HCV and treatment efficacy [46]. In this study, HCV viral loads were negatively correlated with PLT but positively correlated with TPO. Previous studies of HCV infection revealed that the virus binds to glycoproteins on platelet surfaces; glycoprotein apparently plays a role in viral transport and in the persistence of ligands on platelet surfaces $[39,47]$. Therefore, we speculate that HCV affects the PLT in circulating blood, which then affects TPO secretion.

The ROC curve analysis is widely used to measure the discriminatory power of diagnostic or prognostic tests [48]. In the current study, ROC curve analysis revealed that the optimal subset of haematological indices (RBC, MCHC, PLT,
P-LCR, and MONO) had an AUC of 0.822 (specificity = 0.768 ; sensitivity $=0.757$ ), which confirmed that this subset was a significant predictor of HCV. Some patients classified as having suspected $\mathrm{HCV}$ infection in this study had normal to low-normal RBC and PLT values. Again, however, some cases included in this analysis may have been classified as "healthy" because they had not yet been excluded by a blood donation screening test. One solution is the use of a computer program to improve accuracy in screening candidates for further $\mathrm{HCV}$ confirmatory tests.

\section{Conclusions}

Hepatitis $\mathrm{C}$ virus is the main risk factor for HCC in Western Europe, North America, and Asia. Almost all HCVassociated HCCs occur in patients with cirrhosis. Antiviral treatment is the only available option for preventing or delaying the occurrence of HCC in patients with chronic HCV infection. In the early stages of HCC, malignant behavior may not have a strong correlation with histological appearance. The use of improved HCV screening methods that can detect infection in early stage not only limits further spread but also reduces the overall number of chronic HCV cases and substantially reduces the incidence of HCC.

Currently, the most urgent tasks are identifying potential markers for screening or early diagnosis of HCC among high-risk individuals with chronic hepatitis $\mathrm{C}$ and identifying target molecules for the treatment and prevention of HCVassociated HCC. The analytical results of this study suggest that cases in which RBC, MCHC, PLT, P-LCR, and MONO exceed the optimal cut-off values require further confirmation such as by HCV NAT. The data obtained in this study can be used to improve accuracy in screening the general population for potential cases of HCV infection. To enhance the early detection of HCV infection, further studies are needed to modify and improve existing screening procedures and to develop convenient supplemental screening flowcharts. Until then, the findings of this study should be applied cautiously.

\section{Abbreviations}

ALT: $\quad$ Alanine transaminase

ANCOVA: Analysis of covariance

CBC: $\quad$ Complete blood count

ELISA: Enzyme-linked immunosorbent assay

Hb: Hemoglobin 
$\begin{array}{ll}\text { HCC: } & \text { Hepatocellular carcinoma } \\ \text { HCT: } & \text { Hematocrit } \\ \text { HBV: } & \text { Hepatitis B virus } \\ \text { HCV: } & \text { Hepatitis C virus } \\ \text { MCHC: } & \text { Mean corpuscular haemoglobin concentration } \\ \text { MONO: } & \text { Monocyte count } \\ \text { NAT: } & \text { Nucleic acid test } \\ \text { MPV: } & \text { Mean platelet volume } \\ \text { PCR: } & \text { Polymerase chain reaction } \\ \text { P-LCR: } & \text { Platelet-large cell ratio } \\ \text { PCT: } & \text { Plateletcrit } \\ \text { PDW: } & \text { Platelet distribution width } \\ \text { PLT: } & \text { Platelet count } \\ \text { RBC: } & \text { Red blood cell count } \\ \text { RIBA: } & \text { Recombinant immunoblot assay } \\ \text { ROC: } & \text { Receiver operating characteristic } \\ \text { AUROC: } & \text { Area under ROC curve } \\ \text { TPO: } & \text { Thrombopoietin } \\ \text { WBC: } & \text { White blood cell count. }\end{array}$

\section{Conflict of Interests}

No author has competing interests in the publication of this study.

\section{Authors' Contribution}

Pei-Yu Chu contributed to study design and paper revision. Mei-Hua Tsai and Bintou Sanno-Duanda contributed to analysis, interpretation of data, and paper drafting. KueiHsiang Lin performed conception and overall coordination of study and paper revision. Kuan-Tsou Lin performed data analysis and experiments. Chi-Ming Hung and Hung-Shiang Cheng carried out experiments. Yu-Chang Tyan, Ming-Hui Yang, and Shyng-Shiou Yuan contributed to interpretation of data. All authors have read and approved the final paper. MeiHua Tsai and Kuei-Hsiang Lin equal contributed to this work.

\section{Acknowledgments}

The authors gratefully acknowledge Dr. Ren-Chin Jang for his dedication and commitment to this collaborative study. The Statistical Analysis Laboratory, Department of Medical Research, Kaohsiung Medical University Hospital, Kaohsiung Medical University, is greatly appreciated for helpful suggestions and guidance throughout the paper revision process. This study was funded by the Taiwan Blood Services Foundation (97-01-KS), Kaohsiung Medical University (KMU-M110018, Aim for the Top 500 Universities Grant KMU-O104003, and Aim for the Top Journal Grant KMUDT103010), Ministry of Health and Welfare (MOHW103-TDB-111-05), and the National Science Council, Taiwan (NSC102-2320-B-037-017). This study was approved by the Ethics Committee of the Taiwan Blood Services Foundation.

\section{References}

[1] B. C. Cowie, K. S. Carville, and J. H. MacLachlan, "Mortality due to viral hepatitis in the global burden of disease study 2010: new evidence of an urgent global public health priority demanding action," Antiviral Therapy, vol. 18, no. 8, pp. 953-954, 2013.

[2] H. B. El-Serag and K. L. Rudolph, "Hepatocellular carcinoma: epidemiology and molecular carcinogenesis," Gastroenterology, vol. 132, no. 7, pp. 2557-2576, 2007.

[3] J. McCombs, T. Matsuda, I. Tonnu-Mihara et al., "The risk of long-term morbidity and mortality in patients with chronic hepatitis C: results from an analysis of data from a department of veterans affairs clinical registry," JAMA Internal Medicine, vol. 174, no. 2, pp. 204-212, 2014.

[4] C. Trepo, "A brief history of hepatitis milestones," Liver International, vol. 34, supplement 1, pp. 29-37, 2014.

[5] C.-H. Chen, P.-M. Yang, G.-T. Huang, H.-S. Lee, J.-L. Sung, and J.-C. Sheu, "Estimation of seroprevalence of hepatitis B virus and hepatitis $C$ virus in Taiwan from a large-scale survey of free hepatitis screening participants," Journal of the Formosan Medical Association, vol. 106, no. 2, pp. 148-155, 2007.

[6] J. H. Wang, S. N. Lu, J. C. Wu et al., "A hyperendemic community of hepatitis B virus and hepatitis C virus infection in Taiwan," Transactions of the Royal Society of Tropical Medicine and Hygiene, vol. 93, no. 3, pp. 253-254, 1999.

[7] C. A. Sun, H. C. Chen, C. F. Lu et al., "Transmission of hepatitis $\mathrm{C}$ virus in Taiwan: prevalence and risk factors based on a nationwide survey," Journal of Medical Virology, vol. 59, no. 3, pp. 290-296, 1999.

[8] C.-M. Lee, S.-N. Lu, C.-H. Hung et al., "Hepatitis C virus genotypes in southern Taiwan: prevalence and clinical implications," Transactions of the Royal Society of Tropical Medicine and Hygiene, vol. 100, no. 8, pp. 767-774, 2006.

[9] P. Simmonds, F. McOmish, P. L. Yap et al., "Geographical distribution of hepatitis $\mathrm{C}$ virus genotypes in blood donors: an international collaborative survey," Journal of Clinical Microbiology, vol. 32, no. 4, pp. 884-892, 1994.

[10] M.-H. Lee, H.-I. Yang, S.-N. Lu et al., "Chronic hepatitis C virus infection increases mortality from hepatic and extrahepatic diseases: a community-based long-term prospective study," The Journal of Infectious Diseases, vol. 206, no. 4, pp. 469-477, 2012.

[11] K. E. Nelson, "The impact of chronic hepatitis $\mathrm{C}$ virus infection on mortality," Journal of Infectious Diseases, vol. 206, no. 4, pp. 461-463, 2012.

[12] J. W. Ward, "The hidden epidemic of hepatitis $C$ virus infection in the United States: occult transmission and burden of disease," Topics in Antiviral Medicine, vol. 21, no. 1, pp. 15-19, 2013.

[13] N. Mühlberger, R. Schwarzer, B. Lettmeier, G. Sroczynski, S. Zeuzem, and U. Siebert, "LHCV-related burden of disease in Europe: a systematic assessment of incidence, prevalence, morbidity, and mortality," BMC Public Health, vol. 9, article 34, 2009.

[14] B. D. Smith, R. L. Morgan, G. A. Beckett et al., "Recommendations for the identification of chronic hepatitis $\mathrm{C}$ virus infection among persons born during 1945-1965," MMWR: Recommendations and Reports, vol. 61, no. RR-4, pp. 1-32, 2012.

[15] L. B. Seeff, "Natural history of chronic hepatitis C," Hepatology, vol. 36, no. 5, supplement 1, pp. S35-S46, 2002.

[16] F.-B. Wu, H.-Q. Ouyan, X.-Y. Tang, and Z.-X. Zhou, "Doubleantigen sandwich time-resolved immunofluorometric assay for the detection of anti-hepatitis $\mathrm{C}$ virus total antibodies with improved specificity and sensitivity," Journal of Medical Microbiology, vol. 57, no. 8, pp. 947-953, 2008.

[17] M. A. El Barbary, A. E. M. Saad, F. M. Attia et al., "Thrombocytopenia in patients with chronic hepatitis $\mathrm{C}$ : a possible role of 
hcv on platelet progenitor cell maturation," Angiology, vol. 61, no. 3, pp. 304-313, 2010.

[18] T. L. Kauf, D. R. Nelson, J. Schelfhout, J. A. Delaney, and P. F. Wang, "Trends in the prevalence of thrombocytopenia among individuals iInfected with hepatitis C Virus in the United States, 1999-2008," BMC Research Notes, vol. 5, article 142, 2012.

[19] M.-C. Tsai, K.-M. Kee, Y.-D. Chen et al., "Excess mortality of hepatocellular carcinoma and morbidity of liver cirrhosis and hepatitis in HCV-endemic areas in an HBV-endemic country: geographic variations among 502 villages in southern Taiwan," Journal of Gastroenterology and Hepatology (Australia), vol. 22, no. 1, pp. 92-98, 2007.

[20] C.-S. Wang, W.-J. Yao, S.-T. Wang, T.-T. Chang, and P. Chou, "Strong association of hepatitis $\mathrm{C}$ virus (HCV) infection and thrombocytopenia: implications from a survey of a community with hyperendemic HCV infection," Clinical Infectious Diseases, vol. 39, no. 6, pp. 790-796, 2004.

[21] X. Li, L. J. Jeffers, C. Garon et al., "Persistence of hepatitis C virus in a human megakaryoblastic leukaemia cell line," Journal of Viral Hepatitis, vol. 6, no. 2, pp. 107-114, 1999.

[22] E. Giannini, F. Botta, P. Borro et al., "Relationship between thrombopoietin serum levels and liver function in patients with chronic liver disease related to hepatitis $\mathrm{C}$ virus infection," The American Journal of Gastroenterology, vol. 98, no. 11, pp. 25162520, 2003.

[23] T. Kawasaki, A. Takeshita, K. Souda et al., "Serum thrombopoietin levels in patients with chronic hepatitis and liver cirrhosis," The American Journal of Gastroenterology, vol. 94, no. 7, pp. 1918-1922, 1999.

[24] P. Hobisch-Hagen, W. Jelkmann, A. Mayr et al., "Low platelet count and elevated serum thrombopoietin after severe trauma," European Journal of Haematology, vol. 64, no. 3, pp. 157-163, 2000.

[25] A. Karmen, F. Wróblewski, and S. LaDue, "Transaminase activity in human blood," The Journal of Clinical Investigation, vol. 34, no. 1, pp. 126-131, 1955.

[26] C. Puoti, R. Castellacci, F. Montagnese et al., "Histological and virological features and follow-up of hepatitis $\mathrm{C}$ virus carriers with normal aminotransferase levels: the Italian prospective study of the asymptomatic C carriers (ISACC)," Journal of Hepatology, vol. 37, no. 1, pp. 117-123, 2002.

[27] J. Cohen, “The scientific challenge of hepatitis C", Science, vol. 285, no. 5424, pp. 26-30, 1999.

[28] J. A. Chiavetta, M. Escobar, A. Newman et al., "Incidence and estimated rates of residual risk for HIV, hepatitis C, hepatitis $\mathrm{B}$ and human T-cell lymphotropic viruses in blood donors in Canada, 1990-2000," Canadian Medical Association Journal, vol. 169 , no. 8, pp. 767-773, 2003.

[29] N. Afdhal, J. McHutchison, R. Brown et al., "Thrombocytopenia associated with chronic liver disease," Journal of Hepatology, vol. 48, no. 6, pp. 1000-1007, 2008.

[30] Blood Screening by Blood Center, Taiwan Blood Services Foundation, 2008, http://www.blood.org.tw/Internet/main/docDetail.aspx? uid $=6678 \&$ pid $=6389 \&$ docid $=24880$.

[31] Blood Screening by Blood Center, Taiwan Blood Services Foundation, 2009, http://www.sc.blood.org.tw/Internet/main/docDetail.aspx? uid $=6677 \&$ pid $=6389 \&$ docid $=24905$.

[32] C. S. Kitchens, "Thrombocytopenia and thrombosis in disseminated intravascular coagulation (DIC)," Hematology American Society of Hematology Education Program, pp. 240-246, 2009.
[33] K. Crapnell, E. D. Zanjani, A. Chaudhuri, J. L. Ascensao, S. S. Jeor, and J. P. Maciejewski, "In vitro infection of megakaryocytes and their precursors by human cytomegalovirus," Blood, vol. 95, no. 2, pp. 487-493, 2000.

[34] C. Flaujac, S. Boukour, and E. Cramer-Bordé, "Platelets and viruses: an ambivalent relationship," Cellular and Molecular Life Sciences, vol. 67, no. 4, pp. 545-556, 2010.

[35] H. Terada, M. Baldini, S. Ebbe, and M. A. Madoff, "Interaction of influenza virus with blood platelets.," Blood, vol. 28, no. 2, pp. 213-228, 1966.

[36] M. A. Chernesky, R. P. B. Larke, and A. G. G. Turpie, "Interaction between viruses and platelets: requirement of haemolytic activity for platelet aggregation induced by paramyxoviruses," Journal of General Virology, vol. 21, no. 2, pp. 205-213, 1973.

[37] S. Kahane, A. Dvilansky, L. Estok, I. Nathan, Z. Zolotov, and I. Sarov, "Detection of anti-platelet antibodies in patients with idiopathic thrombocytopenic purpura (ITP) and in patients with rubella and herpes group viral infections," Clinical and Experimental Immunology, vol. 44, no. 1, pp. 49-56, 1981.

[38] J. Winiarski, "Platelet antigens in varicella associated thrombocytopenia," Archives of Disease in Childhood, vol. 65, no. 1, pp. 137-139, 1990.

[39] A. Zahn, N. Jennings, W. H. Ouwehand, and J.-P. Allain, "Hepatitis $C$ virus interacts with human platelet glycoprotein VI," Journal of General Virology, vol. 87, no. 8, pp. 2243-2251, 2006.

[40] S. Scott, H. J. Reimers, M. A. Chernesky et al., "Effect of viruses on platelet aggregation and platelet survival in rabbits," Blood, vol. 52, no. 1, pp. 47-55, 1978.

[41] T. Bik, I. Sarov, and A. Livne, "Interaction between vaccinia virus and human blood platelets," Blood, vol. 59, no. 3, pp. 482487, 1982.

[42] S. Wang, R. He, J. Patarapotikul, B. L. Innis, and R. Anderson, "Antibody-enhanced binding of dengue-2 virus to human platelets," Virology, vol. 213, no. 1, pp. 254-257, 1995.

[43] I. N. Gavrilovskaya, M. Shepley, R. Shaw, M. H. Ginsberg, and E. R. Mackow, " $\beta_{3}$ integrins mediate the cellular entry of hantaviruses that cause respiratory failure," Proceedings of the National Academy of Sciences of the United States of America, vol. 95, no. 12, pp. 7074-7079, 1998.

[44] A. Scaradavou, "HIV-related thrombocytopenia," Blood Reviews, vol. 16, no. 1, pp. 73-76, 2002.

[45] C.-Y. Dai, C.-K. Ho, J.-F. Huang et al., "Hepatitis C virus viremia and low platelet count: a study in a hepatitis B \& C endemic area in Taiwan," Journal of Hepatology, vol. 52, no. 2, pp. 160-166, 2010.

[46] M. Martell, J. Gomez, J. I. Esteban et al., "High-throughput realtime reverse transcription-PCR quantitation of hepatitis $C$ virus RNA," Journal of Clinical Microbiology, vol. 37, no. 2, pp. 327332, 1999.

[47] S. Hamaia, C. Li, and J.-P. Allain, “The dynamics of hepatitis C virus binding to platelets and 2 mononuclear cell lines," Blood, vol. 98, no. 8, pp. 2293-2300, 2001.

[48] J. Gu, S. Ghosal, and A. Roy, "Bayesian bootstrap estimation of ROC curve," Statistics in Medicine, vol. 27, no. 26, pp. 5407-5420, 2008. 


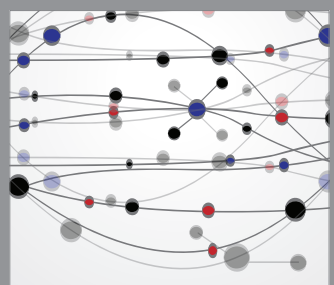

The Scientific World Journal
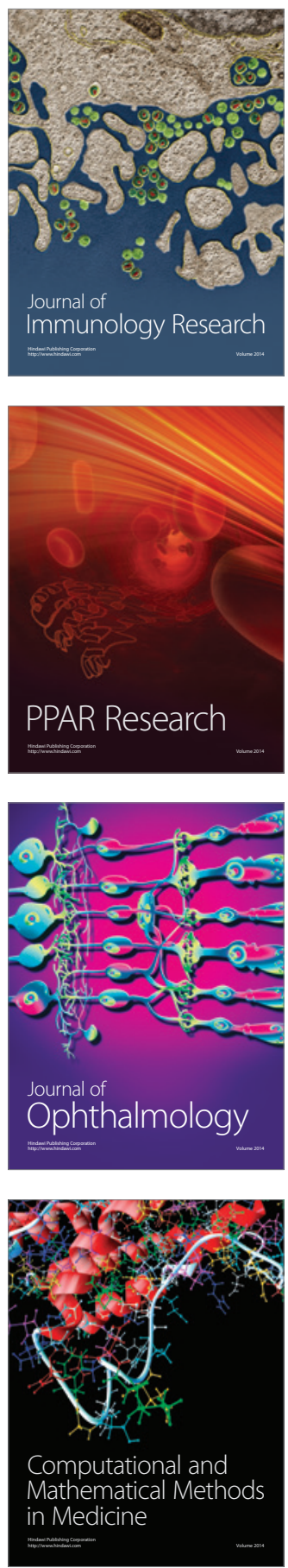

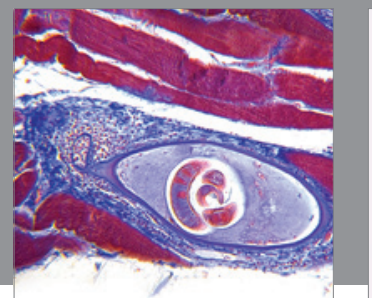

Gastroenterology

Research and Practice
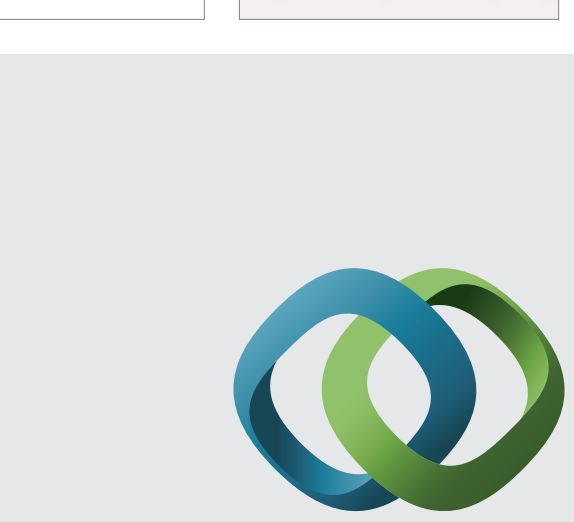

\section{Hindawi}

Submit your manuscripts at

http://www.hindawi.com
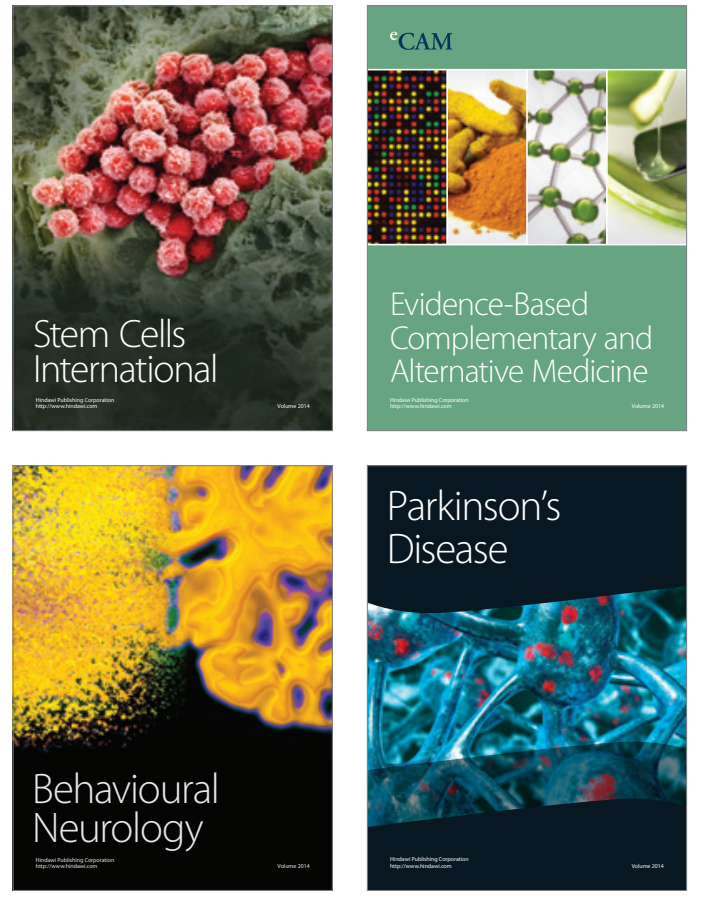
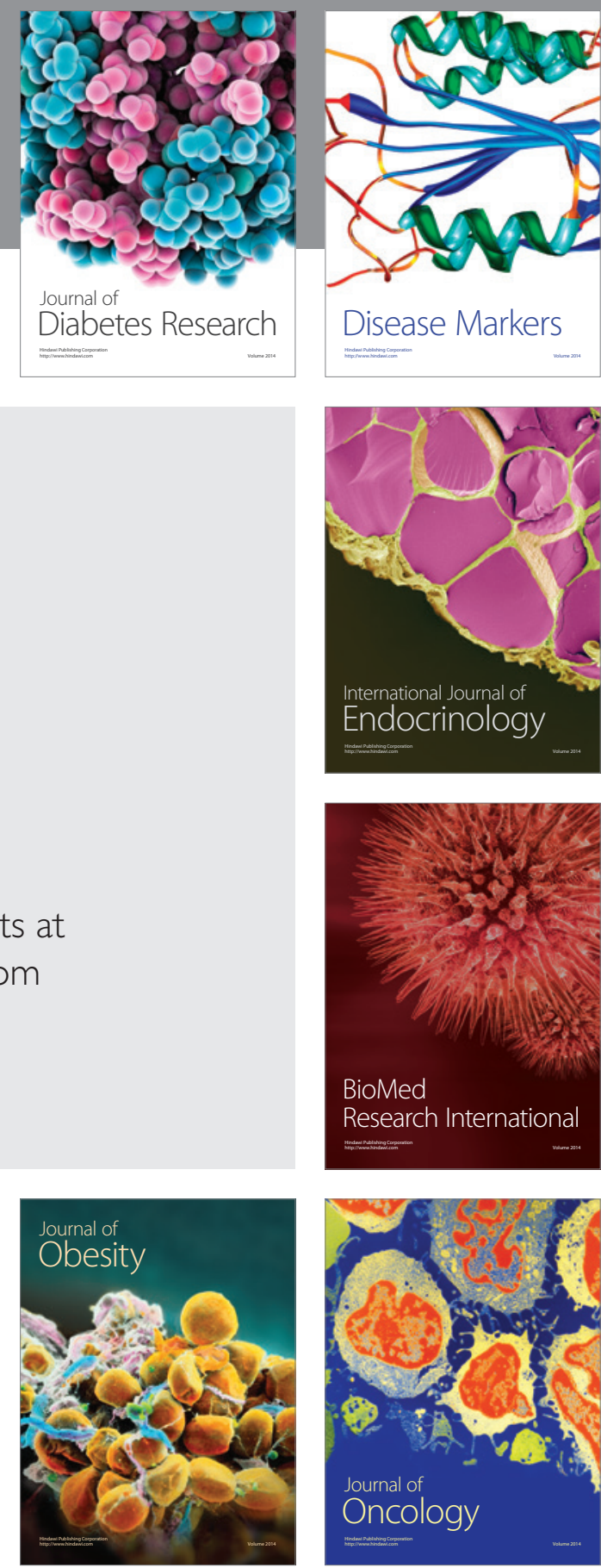

Disease Markers
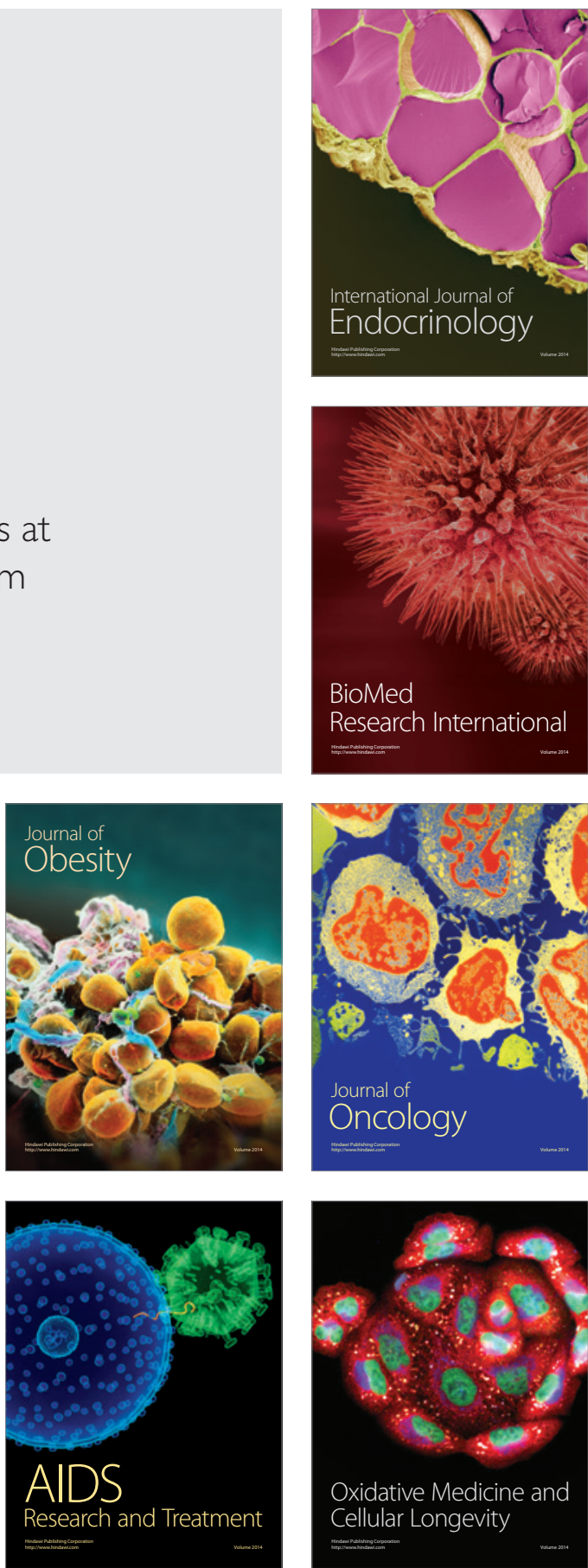